\title{
Bártolo, José (coord.) (2015), Design Português
}

\section{Pedro Quintela}

\section{(2) OpenEdition}

\section{Journals}

\section{Edição electrónica}

URL: http://journals.openedition.org/rccs/6329

DOI: $10.4000 /$ rccs.6329

ISSN: 2182-7435

\section{Editora}

Centro de Estudos Sociais da Universidade de Coimbra

Edição impressa

Data de publição: 1 maio 2016

Paginação: 256-258

ISSN: 0254-1106

\section{Refêrencia eletrónica}

Pedro Quintela, «Bártolo, José (coord.) (2015), Design Português », Revista Crítica de Ciências Sociais [Online], 109 | 2016, posto online no dia 18 maio 2016, consultado o 25 setembro 2020. URL : http:// journals.openedition.org/rccs/6329; DOI : https://doi.org/10.4000/rccs.6329 


\section{Recensões}

\section{Zembylas, Tasos (org.) (2014), Artistic Practices. Social Interactions and Cultural Dynamics. New York: Routledge, 206 pp.}

Apesar da familiaridade de muitos com o que se designa por práticas sociais, Tasos Zembylas defende que deve compreender-se o primeiro plano das práticas de maneira bem diferente da forma convencional. De salientar, também, a chamada de atenção do autor sobre a dualidade inerente ao conceito/noção de prática artística - refletida no título da obra e em alguns capítulos desta antologia -, dado este termo possuir um significado específico nas artes (sendo por isso "nativo"): a prática como a forma como o artista compromete o seu próprio trabalho em prol do processo criativo. Na verdade, esta dualidade, manifesta em vários dos contributos que integram este trabalho antológico, legitimará o entendimento de que esta obra é de interesse para os sociólogos das artes e da cultura e para os que apreciem e se interessem pela noção de prática, sejam eles provenientes da sociologia ou de outras áreas.

Este livro organiza-se em torno da revivificação e reatualização analítica e conceptual do conceito de prática aplicado ao campo artístico. Concretamente, aborda as práticas artísticas e a sua importância na estruturação das artes contemporâneas. Esta abordagem funda-se na perspetiva de que a criação artística é, mais ou menos, um processo aberto (e) incorporado numa esfera social e cultural. Isto implicará que o processo artístico pressupõe um conhecimento vasto, sobretudo dos seus produtores, criadores e mediadores. Deste modo, assume-se que a investigação sociológica do processo de criação artística começará por questionar qual o modo melhor para se penetrar neste processo. A nossa compreensão sobre a prática artística determina se a vemos primeiramente como um produto ou se a entendemos como uma prática, como um termo que refere a uma ordem de atividades conectadas que também possuem uma dimensão ontológica. Neste segundo caso, o objeto de investigação não pode ser exclusivamente discursivo. A lógica da prática não é uma lógica formal; o conhecimento prático deve ser entendido como a capacidade de agir de acordo com uma visão situacional, em vez de um reconhecimento no sentido mais estrito da palavra. A prática ou o conhecimento fundamentado na prática é formado com base na socialização e na experiência, isto é, através da formação, imitação e dos próprios processos de aprendizagem. Este é o alcance deste livro. Tasos Zembylas, mentor e organizador da obra, defende que uma investigação teórica sobre o conhecer artístico implica conceber os processos de criação como objetos complexos, que resultam de uma sinergia de várias formas e elementos de conhecimento - teórico, experiencial, sensorial, etc. Na criação artística, as regras, as convenções e os valores estéticos, as emoções e as motivações - todos componentes indissociáveis do trabalho total final - são integrados. Zembylas nota ainda que existe um certo "esquecimento das práticas" por parte da filosofia e da teoria social. Por um lado, quer no campo das artes, quer no campo das ciências, trabalha-se significativamente ao nível teórico e experimental, 
apresentando-se resultados sem referência ao processo criativo subjacente aos trabalhos realizados naqueles âmbitos - talvez devido ao facto de estas práticas serem autoevidentes para os autores ou devido à preocupação destes em focarem-se mais nos conteúdos e não no modus operandi inerente aos seus feitos/realizações. Por outro lado, parece haver uma desvalorização do corpo enquanto portador, ele próprio, de agency. Na verdade, a tradição racionalista (de inspiração cartesiana) constrói a racionalidade como uma faculdade intelectual/cognitiva, meramente formal, removida da vida quotidiana. Mas independentemente destes dualismos filosófico-teóricos (como, por exemplo, a fenomenologia versus pragmatismo), crê Zembylas que é possível enfatizar a primazia da prática e o papel central do corpo como um "veículo inteligível".

A escolha do tema deste livro - as práticas artísticas - decorre, segundo Zembylas, de várias razões. A primeira razão prende-se, precisamente, com o facto de a sociologia das artes ter vindo a evidenciar as estruturas institucionais e as relações de poder que determinam a visibilidade no mundo das artes e, consequente, os processos de construção da reputação artística. Uma segunda razão assenta na premissa de que o conceito de prática será, teoricamente, bastante promissor no que respeita à superação dos dualismos já referenciados e discutidos - ou seja, a superação da oposição indivíduo/sociedade, tornando possível a análise de atividades e discursos sobre os níveis micro e macro, simultaneamente. A terceira razão reside na defesa de que um olhar mais atento sobre as práticas artísticas poderá contribuir para se apreender a dimensão prática da estética, uma vez que esta tem sido, por um lado, no seio da filosofia, perspetivada por vários pressupostos, e, por outro lado, equacionada pela sociologia tendo por base uma perspetiva extrínseca (assumindo-se que representa um discurso hegemónico no qual se estabelece padrões específicos de avaliação), relegando a existência de uma relação intrínseca da mesma com o processo de criação artística.

A obra organiza-se em duas partes. A primeira, de cariz mais teórico, estrutura-se em quatro capítulos, a saber: "The Concept of Practice and the Sociology of the Arts", do próprio Zembylas; "Art Bundles", de Theodore Schatzki; "Practices of Contemporary Art”, de Nathalie Heinich; e, finalmente, "Artistic Practices as Gendered Practices”, de Marie Buscatto. O primeiro contributo explora o significado de prática para vários autores (desde Aristóteles), propondo Zembylas uma estrutura conceptual para a análise da criação artística como um processo complexo, apresentando uma abordagem complementar às teorias existentes que potencie novos temas para a sociologia das artes. Schatzki apresenta uma abordagem prático-teorética da arte. No terceiro capítulo, Heinich aplica o conceito de paradigma ao mundo das artes, identificando três formas coexistentes de conceptualização e de prática (praxis) das artes visuais: a arte clássica (figurativa e narrativa), a arte moderna (que transgride os padrões de figuração tradicional) e a arte contemporânea (que desafia a própria noção de arte). No último capítulo, recapitulam-se as investigações recentes sobre as relações de género nas artes.

A segunda parte da obra é composta por sete capítulos de natureza mais analítica e aplicados a diferentes subcampos artísticos particulares: arte contemporânea, cinema, street art, literatura, arte pública, dança e música. Assim, no primeiro capítulo desta componente (quinto da obra), Chris Mathieu e Iben Sandal Stjerne analisam a aquisição, o refinamento e abandono das práticas ao longo das carreiras na produção de um filme; tendo por 
referência vários estudos empíricos, procuram demonstrar como as constantes negociações sobre o significado construído em torno das boas e más práticas modificam as atuais, adiantando que estas mudanças das práticas se relacionam, em alguns casos, com as mudanças do próprio ambiente/ /contexto, ao passo que, em outros, dependem de processos internos e resultados decorrentes de determinados caminhos e trajetórias. No capítulo seguinte, Silvana K. Figueroa-Dreher, a propósito da improvisação no jazz, intenta demonstrar o modo como o material musical, a atitude dos músicos e a interação entre eles desempenham um papel fundamental na elucidação/ /compreensão das práticas de improvisação. No capítulo seguinte, Chiara Basseti interpreta o corpo, com a sua experiência e o seu conhecimento incorporado, como uma dimensão fundamental em todas as práticas humanas; tendo por referência a natureza corpórea da performance da dança.

Continuando a percorrer a segunda parte desta antologia, Zembylas centra-se no processo de escrita literária, explorando, primeiramente, o nexus entre a sociologia das artes e a abordagem do conhecimento tácito e discutindo a sua aplicação na investigação empírica sobre o processo artístico criativo; num segundo momento, procura lançar pistas sobre: a criação e integração de ideias criativas, a relevância da experiência, a forma como os escritores enfrentam desafios específicos decorrentes da exposição e da fragilidade dos processos criativos e da influência dos seus pares. No capítulo seguinte, Laurent Thévenot discute as diferentes formas de compromisso em projetos de arte participativa.
A partir de um projeto específico, "Um jardim partilhado em Paris", o autor explora vários aspetos relacionados com aqueles compromissos, a emergência do comunitarismo e formas de justificação de bens comuns. O contributo de Sophia Krzys Acord centra-se na exploração dos processos de preparação e montagem de exposições (curadoria) no sentido de revelar a mediação como resultado de interações que decorrem não só entre os diferentes atores sociais, mas também entre obras de arte, outros objetos e o espaço. Por fim, Graciela Trajtenberg, traz para a discussão a análise de práticas artísticas desenvolvidas à margem do mundo da arte, tomando como exemplo o graffiti, onde as margens respeitam às restrições legais ou à formação artística informal deste domínio específico da prática.

Tal como refere Zembylas (2014: 4), esta antologia inclui várias discussões e análises de práticas artísticas, constituindo-se num esforço coordenado para explorar a complexidade e indeterminação dos processos criativos artísticos. Considera-se que a temática desta obra - o estudo das práticas artísticas - é muito conveniente, tendo em conta o crescente interesse nas mesmas, visível em vários campos da sociologia, dos média e da sociedade em geral. Por isso mesmo, nos parece extremamente importante e oportuna a sua publicação, constituindo um contributo muito útil para o alumiamento de trabalhos sociológicos que incidem sobre as práticas artísticas e as práticas sociais em geral, como não acontecia desde os trabalhos de Pierre Bourdieu.

Paula Guerra 


\section{Campbell, Miranda (2013), Out of the Basement. Youth Cultural Production in Practice and in Policy. Montreal \& Kingston/London/Ithaka: McGill- -Queen's University Press, 283 pp.}

Apesar da grande proximidade dos seus objetos de estudo, são ainda relativamente escassas análises e estudos que ambicionam cruzar as questões da juventude, do emprego e da transição para o mercado de trabalho com o processo de crescente culturalização da economia, no seio do qual a chamada 'agenda' criativa tem vindo, nas últimas duas décadas, a atingir um particular protagonismo, seduzindo um número cada vez mais expressivo de jovens. No contexto anglo-saxónico, Angela McRobbie foi pioneira, distinguindo-se ao propor um notável cruzamento entre sociologia da juventude e da cultura, os estudos (sub- e pós-)culturais e a economia da cultura.

Out of the Basement resulta da investigação de doutoramento de Miranda Campbell e insere-se justamente nesta linha de investigação, questionando o modo como as políticas públicas têm respondido aos desafios que coloca o facto de um número crescente de jovens construir um trajeto profissional no setor cultural e criativo. Contrariamente às abordagens convencionais, que tendem a estudar o trabalho e emprego em domínios de produção cultural com uma matriz industrial (cinema ou televisão, por exemplo), Campbell debruça-se sobre diferentes percursos juvenis em transição para a idade adulta, centrando a sua análise em carreiras e projetos culturais que assumem um perfil marcadamente pessoal e/ou que assentam numa base comunitária, de pequena escala, frequentemente desenvolvidos de um modo independente e do-it-yourself (ou, como prefere a autora, do-it-with-others). Através de um aturado trabalho empírico, assente na recolha e análise de histórias de vida, realização de estudos de caso, análise documental de fontes diversificadas e ainda na observação direta, a autora reflete sobre o modo como estes jovens canadianos (dos 18 aos 35 anos) almejam trabalhar no setor cultural e criativo de forma independente e autónoma, criando soluções de autoemprego de pequena escala, construindo e negociando os seus percursos pessoais e profissionais. Simultaneamente, Campbell analisa as políticas públicas - sobretudo nos domínios da cultura, educação, juventude e planeamento urbano -, discutindo de que modo têm potenciado ou constrangido os percursos e iniciativas dos jovens. Ao longo do livro identificam-se, assim, importantes desafios e avança-se mesmo com propostas concretas para uma nova geração de políticas públicas.

Esta obra está estruturada em três partes - Práticas, Estruturas e Iniciativas -, subdividas em sete capítulos, uma introdução e uma conclusão. Evitando uma divisão excessivamente linear, Campbell propõe um diálogo permanente entre teoria e empiria, convidando o leitor a refletir sobre diferentes problemáticas a partir de histórias de vida, excertos de entrevistas ou estudos de casos que, por sua vez, suscitam uma discussão teórica.

A primeira parte do livro centra-se na discussão de três aspetos-chave. Um primeiro aspeto diz respeito às grandes transformações em curso nos domínios da produção, distribuiç̧ão e consumo cultural, dando especial atenção aos impactos da digitalização e uso crescente da Internet na forma como os jovens constroem hoje os seus percursos profissionais e se relacionam com os processos de ensino e aprendizagem. Apresenta-se, em segundo lugar, uma reflexão em torno da transformação do conceito de juventude, articulando-o com 
as profundas mutações do mercado laboral. Num contexto marcado por uma crescente precariedade laboral, explora-se aqui com particular acuidade o crescente fascínio por formas de emprego menos convencionais, mais autónomas e criativas. Num terceiro ponto, Campbell analisa criticamente o posicionamento periférico da juventude num quadro em que 'agenda' criativa domina a esfera política e académica. A autora conclui que as conceções dominantes de indústrias criativas são desadequadas pois, por um lado, tendem a centrar-se nas esferas mais industrializadas do setor, negligenciando atividades de produção cultural de pequena escala, baseadas em abordagens artesanais e do-it-yourself, e, por outro lado, mantêm-se ainda arreigadas a conceções dicotómicas e puristas de criatividade e de trabalho criativo que não têm correspondência com as conceções e práticas dos jovens estudados.

A segunda parte do livro equaciona, em diferentes planos e escalas territoriais (nacional, federal, provincial e municipal), as políticas públicas relacionadas com cultura, educação e juventude. Embora as referências ao Canadá sejam aqui centrais, tecem-se igualmente análises comparativas com outros contextos internacionais (nomeadamente, com o Reino Unido). Campbell apresenta um diagnóstico crítico que, em geral, evidencia o conservadorismo das instituições públicas, as omissões a questões relacionadas com a juventude e denota ainda um preocupante desfasamento face às necessidades específicas que se colocam ao nível da formação e emprego neste setor. Em alternativa, propõe uma nova abordagem ao planeamento das políticas culturais, mais articulada e transversal, capaz de equacionar as relações entre cultura, juventude, educação e desenvolvimento comunitário. Num contexto de crise económica e social, como o atual, Campbell defende que a juventude e as suas atividades culturais e artísticas de escala reduzida e forte enraizamento local deverão beneficiar de um outro reconhecimento político. Argumenta também ser necessário alargar e diversificar os públicos-alvo de medidas e iniciativas de emprego relacionados com a área da cultura.

A terceira e última parte do livro analisa algumas experiências que apontam perspetivas interessantes de novos modelos de organização e resposta aos desafios que hoje se colocam às políticas culturais e educativas. Assim, aborda diferentes iniciativas de jovens que trabalham no setor cultural e criativo e que, de diversos modos, procuram ultrapassar os obstáculos existentes. Para além de identificar boas práticas, Campbell analisa criticamente alguns conceitos-chave que se tornaram hegemónicos neste campo de intervenção (por exemplo o de rede), refletindo em torno das suas limitações e dos mecanismos de exclusão que têm implícitos. Sublinha a necessidade de revisão de algumas orientações de política pública apresentando, nestes três últimos capítulos, várias recomendações concretas para a melhoria dos instrumentos públicos de apoio a jovens produtores e organizações culturais. Nas conclusões, Campbell reitera a urgência de aprofundar o conhecimento das experiências e necessidades concretas dos jovens que pretendem trabalhar no setor cultural e criativo, considerando que este tipo de análises e estudos devem constituir um veículo fundamental para a revisão e aperfeiçoamento das políticas públicas. Neste sentido, defende um posicionamento mais interventivo das ciências sociais, capaz de informar criticamente as políticas públicas através de investigações atualizadas sobre juventude e culturas juvenis, processos de transição para o mercado de trabalho e indústrias culturais e criativas. 
Em suma, este trabalho constitui um contributo muito relevante ao discutir, de forma rigorosa e original, um importante conjunto de questões relacionadas com políticas públicas, juventude e emprego em setores culturais e criativos. Out of the Basement, pelo seu esforço de articulação e reflexão crítica, a partir de fontes técnico-científicas diversificadas e elementos empíricos originais, disponibiliza ao leitor inúmeras pistas para reflexão e intervenção que certamente poderão ser úteis quer a investigadores académicos, quer a quadros técnicos e decisores políticos.

\section{Pedro Quintela}

\section{Bártolo, José (coord.) (2015), Design Português. Vila do Conde: Verso da História, 8 volumes.}

Assistiu-se, nas últimas décadas, a um amplo e crescente reconhecimento da relevância política, económica, cultural e social do design. Contudo, em Portugal este processo tem sido substancialmente mais lento, comparando nomeadamente com outros países europeus, o que se poderá justificar pelos atrasos e as debilidades crónicas que caraterizam o desenvolvimento do seu tecido industrial, pelo caráter relativamente recente do exercício desta profissão e ainda pelas dificuldades em afirmar a sua relevância e autonomia disciplinar. Estes fatores ajudam a explicar a posição secundária a que foi votada a análise histórica do desenvolvimento do design em Portugal até à década de 1990 - se excetuarmos as incursões de historiadores como José-Augusto França ou Manuel Rio-Carvalho em áreas relacionadas com o design (como as artes decorativas, o desenho e a caricatura) -, quando surgem os contributos pioneiros de Maria Helena Souto $(1991)^{1}$ e Rui Afonso Santos (1995). ${ }^{2}$ Sobretudo desde 2000, com o desenvolvimento do ensino e investigação em design em Portugal, inicia-se um processo de "patrimonialização" do design nacional (Quintela, 2014) ${ }^{3}$ que se carateriza, entre outros aspetos, pelo surgimento de vários trabalhos de análise histórica da disciplina, proliferando sobretudo abordagens monográficas ou delimitadas a certos períodos históricos.

É justamente neste quadro que Design Português adquire um especial interesse, assumindo explicitamente "o objetivo de colmatar a quase total ausência de obras de referência sobre a história do design contemporâneo em Portugal”. Composta por oito volumes, semanalmente distribuídos com o jornal Público, entre março e maio de 2015, esta publicação coletiva envolveu investigadores de diferentes gerações, filiações institucionais e formações disciplinares (história de arte, design, ciências da comunicação). Estruturada cronologicamente, abrange o extenso período de 1900 a 2015, incidindo os seis volumes

\footnotetext{
${ }^{1}$ Souto, Maria Helena (1991), “'Design’ em Portugal 1980-1990 - Dispersão Pluralista”, in José-Augusto França (programação e introdução), Portugal moderno. Artes e letras. Lisboa: Pomo, 99-117.

2 Santos, Rui Afonso (1995), “O design e a decoração em Portugal, 1900-1994”, in Paulo Pereira (dir.), História da Arte Portuguesa, Vol. III - Do barroco à contemporaneidade. Lisboa: Círculo de Leitores, 437-505.

3 Quintela, Pedro (2014), "Processos de 'patrimonialização' do design em Portugal: algumas reflexões”, Cabo dos Trabalhos, 10, 1-21. Consultado a 18.04.2016 em http://cabodostrabalhos. ces.uc.pt/n10/documentos/9.1.2_Pedro_Quintela.pdf.
} 
iniciais em duas décadas particulares e os dois últimos tomos dedicando-se à apresentação de uma cronologia detalhada.

Propõe-se uma leitura sequencial da evolução do design em Portugal, combinando a análise do desenvolvimento da disciplina e seus profissionais com o enquadramento do contexto nacional do ponto de vista social, cultural e económico, identificando fatores externos com impacto relevante no desenvolvimento do campo, e ainda considerando as grandes tendências e movimentos internacionais contemporâneos no design (e das artes em geral), no sentido de detetar influências e sintonias. Pretende-se, assim, compreender cada época, identificando os principais intervenientes (designers, ateliers, empresas, etc.), tipologias de encomendas/trabalhos desenvolvidos, evoluções ao nível do ensino e da formação, contextos de representação e discussão pública acerca da disciplina e da sua importância (económica, social, cultura), entre outros aspetos.

O resultado global é bastante satisfatório, apresentando uma análise sistemática da evolução do design em Portugal ao longo do século xx e xxi, amplamente enriquecida por um vasto conjunto de imagens, algumas delas de difícil acesso. Como seria expetável, numa obra com estas caraterísticas, não se apresentam leituras históricas particularmente inovadoras, resultantes de investigações originais e aprofundadas, mas uma síntese histórica que recorre a uma multiplicidade de fontes de informação (embora, lamentavelmente, nem sempre devidamente referenciadas nas notas bibliográficas). Contudo, este aspeto não torna o resultado final menos interessante, sendo de referir o bom equilíbrio de linguagem que aqui se encontra, capaz de comunicar, de forma simultaneamente apelativa e rigorosa, com um público alargado - aspeto fundamental numa publicação distribuída com um jornal de grande tiragem. Design Português constitui, por isso, um contributo importante para enriquecer e alargar o debate acerca da história do design em Portugal.

Importa, contudo, sublinhar certos desequilíbrios que parecem resultar da opção da divisão da obra em volumes, segmentando a análise por pares de décadas. Esta leitura histórica tem, naturalmente, um certo grau de artificialidade, já que muitos destes processos têm características mais profundas, prolongando-se no tempo e exigindo, assim, uma leitura mais alargada. Não admira, portanto, que sejam frequentes as remissões para aspetos referidos em volumes anteriores ou posteriores, o que cria algumas redundâncias e complexifica a leitura.

É também discutível - ainda que compreensível, atendendo ao caráter introdutório da obra - a opção por centrar a análise em percursos individuais (de designers ou atelier), acabando por retirar espaço a outro tipo de leituras, porventura menos "heroicas", que caraterizam muitas das abordagens à história do design (cf. Julier, 2008: 43-47), ${ }^{4}$ mas não menos interessantes. Observando o período mais contemporâneo, por exemplo, parece haver uma clara insistência em focar os percursos de alguns designers gráficos com trabalhos para clientes ligados às artes e à cultura, descurando outras dimensões do trabalho nesta área, porventura menos reconhecidas entre pares mas não menos fundamentais, ligadas à criação de elementos de comunicação visual de cariz mais quotidiano. Com efeito, se a comunicação marcadamente "comercial" está muito presente na análise das décadas iniciais do século xx, esta vai-se tornando

\footnotetext{
${ }^{4}$ Julier, Guy (2008), The Culture of Design. London: Sage [2. ${ }^{a}$ ed.].
} 
cada vez mais rarefeita à medida que nos aproximamos do século xxi - quando, paradoxalmente, talvez nunca como hoje a publicidade e o marketing tenham estado tão presentes na nossa sociedade.

Por outro lado, se a aposta em abordar os períodos históricos mais contemporâneos constitui certamente um dos aspetos mais interessantes e diferenciadores deste trabalho, contém alguns riscos que talvez pudessem ter sido mais ponderados. Em particular, a leitura do volume dedicado ao período mais recente (2000/2015) revela, por vezes, a necessidade de uma melhor explicitação das opções tomadas na seleção de obras, projetos, iniciativas, ateliers e designers. Este esforço argumentativo teria sido importante para evidenciar o distanciamento do autor, José Bártolo, relativamente a um período em que tem estado intensamente envolvido enquanto professor e investigador universitário, crítico, comissário, blogger e editor.
Por último, a ausência de uma conclusão constitui outro ponto menos positivo, pois permitiria uma melhor articulação das muitas questões e reflexões levantadas pelos autores, evidenciando algumas das grandes linhas de força para pensar o processo de emergência, desenvolvimento e institucionalização do design em Portugal. Esta síntese final poderia ainda tornar mais clara a leitura comparativa com o contexto internacional.

Apesar dos aspetos anteriormente referidos, importa concluir destacando novamente o notável trabalho desenvolvido por todos os autores que colaboraram em Design Português, sublinhando que esta obra constitui um ponto de partida bastante útil para quem pretenda aprofundar o estudo desta temática, abrindo perspetivas de pesquisa para um conjunto de novas discussões e debates.

Pedro Quintela

\section{Paula Guerra}

Faculdade de Letras da Universidade do Porto

Via Panorâmica, s/n, 4150-564 Porto, Portugal

Contacto: pguerra@letras.up.pt

\section{Pedro Quintela}

Centro de Estudos Sociais, Universidade de Coimbra

Colégio de S. Jerónimo, Largo D. Dinis, Apartado 3087, 3000-995 Coimbra, Portugal

Contacto: pedroquintela@ces.uc.pt 